University of Nebraska - Lincoln

DigitalCommons@University of Nebraska - Lincoln

Robert G. Fuller Publications and Presentations Research Papers in Physics and Astronomy

January 1981

\title{
How Do College Students Solve Proportion Problems?
}

Melvin C. Thorton

University of Nebraska - Lincoln

Robert Fuller

rfuller@neb.rr.com

Follow this and additional works at: https://digitalcommons.unl.edu/physicsfuller

Part of the Physics Commons

Thorton, Melvin C. and Fuller, Robert, "How Do College Students Solve Proportion Problems?" (1981). Robert G. Fuller Publications and Presentations. 24.

https://digitalcommons.unl.edu/physicsfuller/24

This Article is brought to you for free and open access by the Research Papers in Physics and Astronomy at DigitalCommons@University of Nebraska - Lincoln. It has been accepted for inclusion in Robert G. Fuller Publications and Presentations by an authorized administrator of DigitalCommons@University of Nebraska - Lincoln. 


\title{
How Do College Students Solve Proportion Problems?
}

\author{
Melvin C. Thornton and Robert G. Fuller \\ University of Nebraska, Lincoln, Nebraska
}

\begin{abstract}
Problems which could be solved using proportional reasoning were administered nationwide by college faculty to their own science classes during a three year period. The reasoning of more than 8000 students covering three sections of the country was classified as concrete, transitional, or formal using Piagetian categories. Data from the West closely replicated that from the Midwest on similar metric conversion tasks. Student performance changed noticeably with a different problem format. The percentages of students using a ratio formula, ratio attempt, or intuitive methods of solution held approximately constant over time, task, and section of the country. The data shows the use of additive and conversion methods of solution depends upon the problem presentation.
\end{abstract}

\section{Introduction}

An almost universal assumption by college science teachers is that their students are capable of using formal or hypothetic-deductive reasoning (Inhelder and Piaget, 1958). However, in class and on examinations when college students are encouraged to show their methods as well as their answers, many inappropriate reasoning patterns are displayed.

During the seventies many researchers (Griffiths, 1976; Killian, 1979; Kolody, 1975; Lawson, Nordland, \& Devito, 1975; McKinnon \& Renner, 1971; Renner \& Lawson, 1973) tested college students in this country and found only 25 to $50 \%$ were consistently using formal reasoning patterns. Yet proportional reasoning, an important pattern of formal thought (Lawson, 1978; Lawson, Karplus, \& Adi, 1978; Renner, 1979; Walker, Hendrix, \& Mertens, 1979) is often assumed to be used by nearly all college science students.

"College Science Teaching and the Development of Reasoning" was the title of a short course offered on the NSF-AAAS Chautauqua circuit to acquaint more college science teachers with the developmental theory of Piaget. The course, co-directed by Robert G. Fuller and Melvin C. Thornton, was given for three academic years beginning in Fall, 1976. Almost three hundred science faculty from over two hundred institutions met for fall and spring sessions to apply some of Piaget's ideas to their own teaching. As part of an interim project between the two sessions these participants gave and evaluated proportion problems answered by a large number of students. This note reports and comments upon the data which were obtained.

Before proceeding the reader should consider these questions: What aspects of a problem encourage students to use proportional reasoning? What kinds of responses to proportionality problems do you expect from college science students? What responses do you evaluate as showing formal reasoning? As not showing formal reasoning? How docs the type of school, subject matter of the course, mathematical prerequisite, or sex of the student relate to the reasoning used? 


\section{The Proportion Problems}

Different written problems requiring proportional reasoning were used in different years. The Wahoo Puzzle (Renner \& Paske, 1977, p. 290) was given to students in the Midwest in Fall 1976. The Recipe Puzzle (Fig. 1) was given to students in the West in Fall 1977. The Shadows Puzzle (Fig. 2) was given to students in the East in Fall 1978.

The student responses were categorized on the reasoning employed, not on a right answerwrong answer dichotomy. The following five point scale was used.

1. Intuitive: No response or a guess with little evidence of reasoning. Example: Can't tell. I'm not good at numbers.

2. Additive: Adds or subtracts to obtain an answer. Example (Shadows): 8 is to 6 as 18 is to 16.

3. Ratio attempt: Attempts a ratio but fails for reasons other than arithmetic: wrong ratio, can't solve for $x$, etc. Example (Recipe): May try to find how many times 99 goes into 231, what remainder will exist, then somehow try to convert the $33 \mathrm{ml}$ remainder into teaspoons.

4. Ratio formula: Uses proportional reasoning to set up an equation and then solve for unknown. Example (Shadows): $6 / 8=x / 18$ so $x=(6 / 8) 18$ or $13 \frac{1}{2}$ feet.

5. Conversion: Introduces a new quantity as a conversion factor then multiplies or divides. Example (Shadows): The height is $6 / 8$ or $75 \%$ of the shadow so the tree is $0.75 \times 18=$ 13.5 feet high.

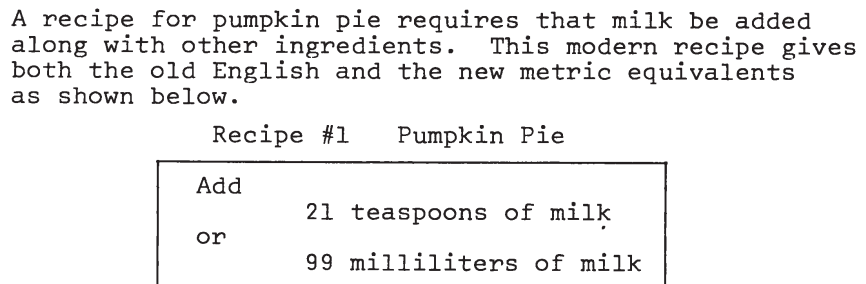

Fig. 1. The Recipe Puzzle. 


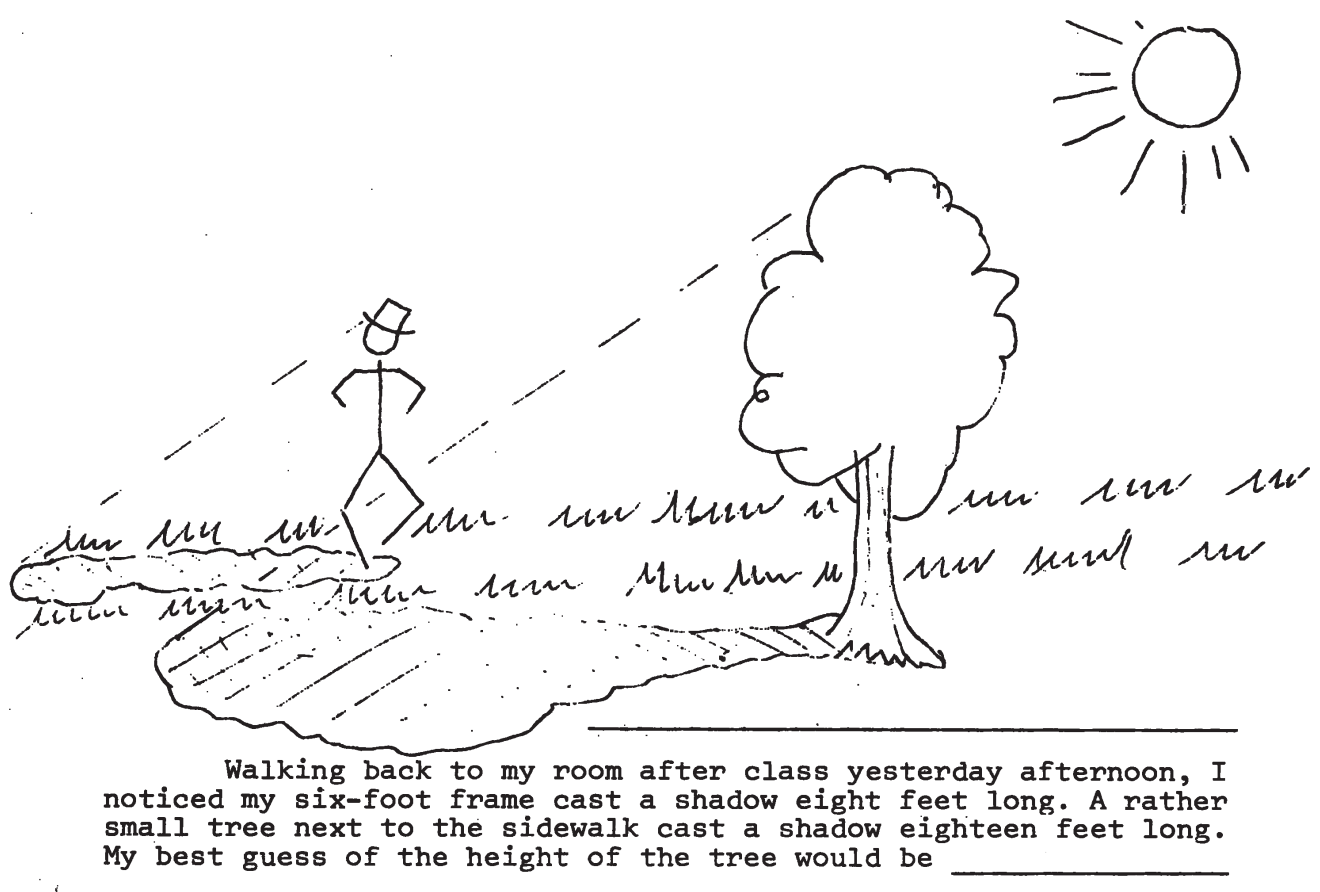

Please explain the reasoning you used to find your answer:

Fig. 2. The Shadows Puzzle.

Note that this five point scale is quite close to those used by Karplus, Adi, and Lawson (in press) and Renner and Paske (1977). Responses of types 1 and 2 were considered as displays of concrete reasoning. A type 3 response was not clearly indicative of either concrete or formal reasoning and was labeled transitional. Responses of types 4 and 5 were assumed to show formal reasoning. The numbering should not be interpreted as meaning a 5 -response is superior .to a 4-response. Both 4 and 5 responses reveal an understanding of the ratio-concept. Renner and Paske suggest a 4-response shows a more sophisticated level of thought than does a 5 because it makes overt use of proportion. On the other hand a 4 could result from applying a memorized algorithm without understanding why and a 5 involves the introduction of a new quantity for the solution. In any case both approaches give the same result but by identifiably distinct reasoning. .

Table I gives a summary of the classes where the problems were given. Note that most of the classes were in science and the average size was approximately 30 students.

Student responses, rounded to the nearest percent, on the three problems are summarized in Table II. 
TABLE I

Numbers of Classes Tested, by Subject Area

\begin{tabular}{lccc}
\hline $\begin{array}{l}\text { Subject } \\
\text { Area }\end{array}$ & $\begin{array}{l}\text { Wahoo } \\
1976 \text { Midwest }\end{array}$ & $\begin{array}{l}\text { Recipe } \\
1977 \text { West }\end{array}$ & $\begin{array}{c}\text { Shadows } \\
1978 \text { East }\end{array}$ \\
\hline $\begin{array}{l}\text { Chemistry } \\
\text { Life Sciences }\end{array}$ & 18 & 31 & 36 \\
Mathematics & 17 & 16 & 25 \\
Physical Sciences & 12 & 19 & 8 \\
Others & 7 & 24 & 7 \\
& & 19 & 99 \\
Total Classes & 75 & 109 & 2919 \\
Total Students & 2455 & 3020 & \\
& & & \\
\hline
\end{tabular}

TABLE II

Responses to Proportion Problems, Categorized by Piagetian Labels

\begin{tabular}{lcccc}
\hline Puzzle & & \multicolumn{2}{c}{ Percent of Responses } & \\
& Concrete & Transitional & Formal & N \\
\hline Wahoo (Midwest) & 12 & 11 & 77 & 2455 \\
Receipe (West) & 13 & 9 & 78 & 3020 \\
Shadows (East) & 29 & 11 & 60 & 2919 \\
\hline
\end{tabular}

\section{Discussion}

Since the problems were given in separate parts of the country a year apart and to different students, the closeness of the percentages for the Wahoo and Recipe results is of interest. A different proportions problem given by Karplus, Adi and Lawson (in press) to 86 freshmen and sophomores in a nonmajors physical science course at the University of California-Berkeley gave similar results: concrete $20 \%$, transitional $6 \%$, and formal $74 \%$. Note that the fraction of responses displaying a good grasp of the ratio concept is fairly constant at about three-fourths.

In 1978 the Shadows Puzzle was expected to replicate the earlier data, but it did not. Why should that problem give such different results? One would think that the students on the East coast are as well prepared as those from the West or Midwest. Looking closely at the methods of solution suggests an alternative explanation. Table III gives the student responses in terms of the five point scale.

The difference in the Wahoo-Recipe performance compared with the Shadows is mainly in the additive and conversion methods. There was a substantial drop in the percentage of students using conversion and a corresponding increase in the percentage of students using the additive method. What makes the additive method much more tempting in the Shadows Puzzle? In response to this question, the professors who evaluated their students' answers to these problems suggested several contributing factors: 
TABLE III

Responses to Proportion Problems, Categorized by Methods of Solution

\begin{tabular}{llllll}
\hline & \multicolumn{2}{c}{$\begin{array}{l}\text { Percent of Responses } \\
\text { Puzzle }\end{array}$} & Intuitive/Additive/Ratio Attempt/Ratio Formula/Conversion \\
\hline Wahoo (Midwest) & 6 & 6 & 11 & 47 & 30 \\
Recipe (West) & 9 & 4 & 9 & 55 & 23 \\
Shadows (East) & 8 & 21 & 11 & 51 & 10 \\
\hline
\end{tabular}

(a) The printed format of the Wahoo-Recipe Puzzles strongly suggests use of a ratio. The quantities are expressed in numerals, the information is displayed in two boxes which are indicated to be equal. The 21 appears directly over the 99 and a blank representing the unknown is directly over the 231 . The numbers are fairly large so the differences are not immediately obvious. An exact number is expected indicating paper-pencil computation is necessary. Both problems involve changing metric to English measurements which may suggest a conversion factor .

(b) The Shadows Puzzle is more obviously a "word problem." The visual clue of similar triangles may be missed by many students. The numerical data is not displayed and each number is written in English, not in numerals. The difference of two feet between the six foot person and eight foot shadow is automatically noticed and tempting to use. The problem asks for a best guess rather than assuming an exact numerical answer.

In none of the three puzzles were the students told it was a proportion problem or that ratios were to be used. The clues to the solution were contained in the written presentation of the problem. The data does indicate a distinct difference in the effectiveness of these clues. Does this difference vary with some obvious parameters of the students?

Data on the Recipe and Shadows Puzzles were compared with regard to these variables: kind of science course, level of science course, assumed mathematics prerequisite, type of school, and sex of student. For all variables the significant change from the Recipe data to the Shadows data was a drop in the percentage using the conversion factor and arise in the percentage using the additive method. For science courses requiring more than college algebra, this change was relatively small. The sex of the student did make a quantitative difference in the change. Males went from 3\% (additive) and 24\% (conversion) on the Recipe to 13\% (additive) and 12\% (conversion) on Shadows. For females the data was 5\% (additive) and 23\% (conversion) on Recipe to $28 \%$ (additive) and $8 \%$ (conversion) on Shadows.

\section{Conclusions and Implications}

Several conclusions can be drawn.

(1) College students use a variety of problem solving approaches to proportion problems.

(2) College teachers ought not to assume that even obvious ratio problems will provoke all students to use proportional reasoning.

(3) The details of the problem statement influence students' use of proportional reasoning.

(4) Additive reasoning is used by many students in inappropriate situations. 
We have found these data illuminate the difficulties many students have with a variety of numerical problems in our classes. For example, the additive method of solution for proportion problems often occurs on examinations. If this does indicate a lack of formal reasoning ability then the Piagetian level of the students must be considered in planning courses. Our own experiences in college classes using the learning cycle model developed by Robert Karplus (Karplus \& Lawson, 1974) provide us with some positive feed back. Six Piagetian-based college programs have found some evidence (ADAPT , 1978) to support the claim that consistent use of active methods can improve students' abilities to evoke satisfactory problem solving schemes.

\section{References}

ADAPT (Accent on Developing Abstract Processes of Thought). Multidisciplinary PiagetianBased Programs for College Freshmen (third edition) Lincoln, NE: Author, 1978.

Griffiths, D. Physics Teaching: Does it hinder intellectual development? American Journal of Physics, 1976, 44, 81-85.

Inhelder, B., \& Piaget, J. The Growth of Logical Thinking from Childhood to Adolescence. New York: Basic Books, 1958.

Karplus, R., Adi, H., \& Lawson, A. E. Intellectual Development Beyond Elementary School VIII: Proportional, Probabilistic, and Correlational Reasoning. School Science and Mathematics, in press.

Karplus, R. \& Lawson, C. A. Science Curriculum Improvement Study, Teachers Handbook. Berkeley, CA; Lawrence Hall of Science, University of California, 1974.

Killian, C. R. Cognitive Development of College Freshmen. Journal of Research in Science Teaching, 1979, 16, 347-350.

Kolody, G. The Cognitive Development of High School and College Science Students. Journal of College Science Teaching, 1975, 5, 20-22.

Lawson, A. E. The Development and Validation of a Classroom Test of Formal Reasoning. Journal of Research in Science Teaching, 1978, 15, 11-24.

Lawson, A. E., Karplus, R., \& Adi, H. The Acquisition of Propositional Logic \& Formal Operational Schemata During the Secondary School Years. Journal of Research in Science Teaching, 1978, 15, 465-478.

Lawson, A. E., Nordland, F. H., \& DeVito, A. Relationship of Formal Reasoning to Achievement, Aptitudes, and Attitudes in Preservice Teachers. Journal of Research in Science Teaching, 1975, 12, 423-431.

McKinnon, J. W., \& Renner, J. W. Are Colleges Concerned with Intellectual Development? American Journal of Physics, 1971, 39, 1047-1052.

Renner, J. W. The Relationships Between Intellectual Development and Written Responses to Science Questions. Journal of Research in Science Teaching, 1979, 16, 279-299.

Renner, J. W ., \& Lawson, A. E. Promoting Intellectual Development Through Science Teaching. The Physics Teacher, 1973, 11, 273.

Renner, J. W ., \& Paske, W. C. Quantitative Competencies of College Students. Journal of College Science Teaching, 1977, 6, 283-292.

Walker, R. A., Hendrix, J. R., \& Mertens, T. R. Written Piagetian Task Instrument: Its Development and Use. Science Education, 1979, 63, 211-220. 